\title{
Cinnamomum loureirii Bark Extract
}

National Cancer Institute

\section{Source}

National Cancer Institute. Cinnamomum loureirii Bark Extract. NCI Thesaurus. Code C107288.

The oil extracted from the bark of Cinnamomum loureiroi. Saig on cinnamon bark oil is used primarily in aromatherapy. 